\title{
Haematological factors associated with proliferative retinopathy in homozygous sickle cell disease
}

\author{
R. J. HAYES, ${ }^{1}$ P. I. CONDON, ${ }^{2}$ AND G. R. SERJEANT ${ }^{2}$ \\ From the ${ }^{2}$ Medical Research Council Laboratories, University of the West Indies, Kingston, \\ Jamaica, and the ${ }^{1}$ Department of Medical Statistics and Epidemiology, London School of \\ Hygiene and Tropical Medicine
}

SUMMARY Haematological indices were investigated in 261 patients with homozygous sickle cell disease, 29 of whom had developed proliferative sickle retinopathy (PSR). After allowing for agerelated effects, male patients with high $\mathrm{Hb}(>9 \mathrm{~g} / \mathrm{dl})$ and low $\mathrm{HbF}(<5 \%)$ levels appeared to constitute a high risk group for PSR. This relationship was not evident in females, PSR being observed in patients with lower $\mathrm{Hb}$ and higher $\mathrm{HbF}$ levels than in the male group. PSR occurred in $14 \%$ of patients aged 40 years or over in this sample.

Small vessel occlusion in homozygous sickle cell (SS) disease results in peripheral retinal infarction and a sequence of vascular events culminating in proliferative sickle retinopathy (PSR). Although less common than in sickle cell haemoglobin $\mathrm{C}$ (SC) disease, PSR represents significant ocular pathology in SS disease especially in older patients. During the course of prospective studies in sickle cell eye disease $\mathrm{e}^{1-5} 29$ patients with SS disease and PSR have been identified. In the present study the haematological indices of patients with and without PSR have been compared in an attempt to search for factors relevant to the development of this complication.

\section{Patients and methods}

Approximately 1000 patients with homozygous sickle cell (SS) disease attend the sickle cell clinic at the University Hospital of the West Indies. By July 1978 ocular examinations had been performed in 261 patients (113 males, 148 females) with ages ranging from 9 to 67 years. The age distribution of this sample was similar for both sexes, and the preponderance of females reflects the pattern in the clinic as a whole.

An initial group of 76 patients examined in August 1970 consisted of relatively asymptomatic, ambulant outpatients with routine clinic appointments. ${ }^{1}$ They were not selected because of ocular complications

Correspondence to Dr G. R. Serjeant, Medical Research Council Laboratories, University of the West Indies, Kingston, Jamaica, WI. and could probably be regarded as a random selection of SS clinic patients. Since then there has been a tendency to concentrate attention on patients with ocular symptoms and those thought likely to develop PSR. Furthermore the number of ocular examinations in any one patient has varied from 1 to 7 . Because of these factors this group of 261 patients will not provide a valid estimate of the prevalence of PSR in the clinic population but may allow the investigation of haematological factors associated with PSR.

Techniques of ocular examination have been previously described, ${ }^{1}$ as have the criteria for the diagnosis of SS disease. ${ }^{6}$ Haematological analyses were based on mean steady-state values for $\mathrm{HbA}_{2}$, $\mathrm{HbF}$, total $\mathrm{Hb}, \mathrm{MCHC}$, MCV, reticulocytes, platelets, irreversibly sickled cell (ISC) count, total bilirubin, and serum iron. The statistical procedures used assume these indices to be normally distributed, and, as the frequency distributions of $\mathrm{HbF}$, reticulocytes, and ISC count were positively skewed, the transformed values $\log _{e}(\% \mathrm{HbF}+4), \log _{e}(\%$ retics +1$)$ and $\log _{e}(\%$ ISC +10$)$ were used to give approximately normal distributions. The constants 4,1 , and 10, added before taking logarithms, were chosen to improve the approximation.

The definition of a patient's 'age' in this study was necessary, since the risk of having acquired PSR would be expected to increase with age, and also because some haematological parameters show age-related variation. Since many patients have had both multiple ocular and haematological examinations, the definition of age was problematical and no definition was entirely satisfactory. The age at which 
Table 1 Sample prevalence of PSR by sex and age group

\begin{tabular}{|c|c|c|c|c|}
\hline \multirow{2}{*}{$\begin{array}{l}\text { Age group } \\
\text { years) }\end{array}$} & \multicolumn{2}{|l|}{ Males } & \multicolumn{2}{|l|}{ Females } \\
\hline & $\begin{array}{l}\text { Number } \\
\text { examined }\end{array}$ & $\begin{array}{l}\text { Number } \\
\text { with PSR }\end{array}$ & $\begin{array}{l}\text { Number } \\
\text { examined }\end{array}$ & $\begin{array}{l}\text { Number } \\
\text { with PSR }\end{array}$ \\
\hline $9-19$ & 19 & $0(0 \%)$ & 28 & $0(0 \%)$ \\
\hline $20-29$ & 37 & $5(14 \%)$ & 50 & $3(6 \%)$ \\
\hline $30-39$ & 25 & $6(24 \%)$ & 31 & $5(16 \%)$ \\
\hline 40 & 32 & $4(13 \%)$ & 39 & $6(15 \%)$ \\
\hline All patients & 113 & $15(13 \%)$ & 148 & $14(9 \%)$ \\
\hline
\end{tabular}

PSR developed, which was most relevant in the PSR group, was only infrequently available, and was inappropriate for patients without PSR. A compromise definition of the age at the patient's last attendance was adopted for this study.

\section{Results}

PREVALENCE AND AGE OF ONSET

Lesions of proliferative retinopathy, either leaking or occluded, were detected in $15 / 113(13 \%)$ male patients and in 14/148 (9\%) females (Table 1). The proportion of patients with PSR was higher in older patients, and there was a tendency in this sample for lesions to be more common in males, though the difference did not reach statistical significance $\left(\chi^{2}=0.6\right.$ with $\left.1 \mathrm{DF}\right)$.

Of the 29 patients with PSR age of onset was recorded prospectively in only 9 cases. Four males aged 20, 26, 27, and 30 years, and 5 females aged
$21,34,39,42$, and 44 years were observed to have PSR which had not been present on ocular examinations conducted 1-3 years previously. The remaining 20 patients had PSR on initial ocular examination.

\section{HAEMATOLOGICAL INDICES}

Means and standard deviations of haematological indices for patients with and without evidence of PSR are shown in Tables 2 and 3. Several patients were found to have extreme values of one or more parameters, and in each analysis the effects of omitting these outliers were examined to ensure that inferences were not unduly influenced by these values.

Indices in patients with and without PSR were compared initially by Student's $t$ test, except in 2 cases where significantly differing sample variances indicated the use of Welch's test. ${ }^{7}$ In males the mean haemoglobin level was significantly higher $(P<0.05)$ and the mean HbF was significantly lower $(P<0.05$, by Welch's test) in the PSR group. Indeed both the mean and standard deviation of $\mathrm{HbF}$ were lower in the PSR group, suggesting that values were clustered in the lower part of the range of this variable. In females neither $\mathrm{Hb}$ nor $\mathrm{HbF}$ differed appreciably between the 2 groups; the only difference reaching statistical significance $(P<0.01$, by Welch's test). was a lower mean serum iron level in the PSR group.

Some of the indices used in the above analyses are known to be strongly correlated, and multiple logistic regression analysis ${ }^{8}$ was therefore used to

Table 2 Comparison of haematological indices in male patients with and without lesions of proliferative retinopathy

\begin{tabular}{|c|c|c|c|c|c|c|c|c|}
\hline \multirow{2}{*}{ Variable } & \multicolumn{3}{|c|}{ With PSR } & \multicolumn{3}{|c|}{ Without PSR } & \multirow{2}{*}{$t$} & \multirow{2}{*}{ Significance } \\
\hline & $n$ & Mean & $S D$ & $n$ & Mean & $S D$ & & \\
\hline Age (years) & 15 & $35 \cdot 5$ & $9 \cdot 8$ & 98 & $30 \cdot 7$ & $12 \cdot 3$ & - & - \\
\hline $\mathrm{HbA}_{2}(\%)$ & 15 & $2 \cdot 98$ & 0.43 & 97 & $2 \cdot 92$ & 0.44 & 0.45 & NS \\
\hline $\log _{e}(\% \mathrm{HbF}+4)$ & 15 & $1 \cdot 92^{1}$ & $0 \cdot 19$ & 98 & $2 \cdot 05^{2}$ & $0 \cdot 34$ & $2 \cdot 17^{*}$ & $P<0.05$ \\
\hline $\mathrm{Hb}(\mathrm{g} / \mathrm{dl})$ & 15 & 8.94 & $1 \cdot 39$ & 98 & $8 \cdot 10$ & $1 \cdot 34$ & $2 \cdot 27$ & $P<0.05$ \\
\hline $\operatorname{MCHC}(\mathrm{g} / \mathrm{dl})$ & 15 & $32 \cdot 8$ & $1 \cdot 2$ & 98 & $32 \cdot 8$ & $1 \cdot 8$ & $-0 \cdot 13$ & NS \\
\hline $\operatorname{MCV}(f)$ & 15 & $88 \cdot 4$ & $7 \cdot 6$ & 95 & $88 \cdot 0$ & $7 \cdot 8$ & 0.15 & NS \\
\hline $\log _{e}(\%$ retics +1$)$ & 15 & $2 \cdot 26^{3}$ & 0.26 & 98 & $2 \cdot 3^{4}$ & $0 \cdot 33$ & $0-\cdot 80$ & NS \\
\hline Platelets $\left(\times 10^{\circ} / 1\right)$ & 14 & 371 & 115 & 82 & 434 & 146 & $-1 \cdot 53$ & NS \\
\hline $\log _{e}(\%$ ISC + 10) & 15 & $2 \cdot 87^{5}$ & $0 \cdot 30$ & 89 & $2 \cdot 97^{8}$ & $\mathbf{0} \cdot 30$ & $-1 \cdot 13$ & NS \\
\hline Tot. bilirubin (mg/dl) & 15 & $3 \cdot 53$ & $2 \cdot 43$ & 96 & 3.45 & 1.98 & $0 \cdot 14$ & NS \\
\hline Serum Fe $(\mu g / d l)$ & 15 & $106 \cdot 7$ & $22 \cdot 0$ & 97 & $95 \cdot 0$ & $26 \cdot 0$ & 1.65 & NS \\
\hline
\end{tabular}

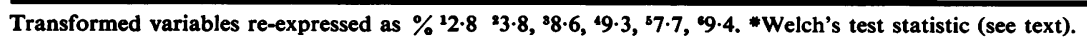


Table 3 Comparison of haematological indices in female patients with and without lesions of proliferative retinopathy

\begin{tabular}{|c|c|c|c|c|c|c|c|c|}
\hline \multirow{2}{*}{ Variable } & \multicolumn{3}{|c|}{ With PSR } & \multicolumn{3}{|c|}{ Without PSR } & \multirow{2}{*}{$t$} & \multirow{2}{*}{ Significance } \\
\hline & $n$ & Mean & $S D$ & $n$ & Mean & $S D$ & & \\
\hline Age (years) & 14 & $39 \cdot 0$ & $13 \cdot 3$ & 134 & $30 \cdot 3$ & $12 \cdot 9$ & 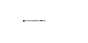 & - \\
\hline $\mathrm{HbA}_{2}(\%)$ & 14 & $2 \cdot 87$ & $0 \cdot 32$ & 128 & $2 \cdot 83$ & 0.47 & $0 \cdot 30$ & NS \\
\hline $\log _{e}(\% \mathrm{HbF}$ & 14 & $2 \cdot 21^{1}$ & $0 \cdot 33$ & 128 & $2 \cdot 22^{2}$ & $0 \cdot 33$ & $-0 \cdot 20$ & NS \\
\hline $\mathrm{Hb}(\mathrm{g} / \mathrm{dl})$ & 14 & $7 \cdot 71$ & 0.83 & 129 & $7 \cdot 84$ & $1 \cdot 08$ & -0.43 & NS \\
\hline $\operatorname{MCHC}(\mathrm{g} / \mathrm{dl})$ & 14 & $32 \cdot 9$ & $1 \cdot 2$ & 129 & $32 \cdot 8$ & $1 \cdot 4$ & $0 \cdot 38$ & NS \\
\hline $\operatorname{MCV}(f)$ & 14 & $90 \cdot 0$ & $7 \cdot 4$ & 125 & $89 \cdot 4$ & $7 \cdot 0$ & $0 \cdot 31$ & NS \\
\hline $\log _{e}(\%$ retics 1$)$ & 14 & $2 \cdot 36^{3}$ & $0 \cdot 35$ & 129 & $2 \cdot 31^{4}$ & $0 \cdot 33$ & $0 \cdot 53$ & NS \\
\hline Platelets $\left(\times 10^{9} / 1\right)$ & 13 & 441 & 110 & 112 & 445 & 150 & -0.09 & NS \\
\hline $\log _{e}(\%$ ISC +10$)$ & 14 & $2 \cdot 89^{5}$ & $0 \cdot 27$ & 112 & $2 \cdot 89^{6}$ & $0 \cdot 30$ & 0.06 & NS \\
\hline Tot. bilirubin $(\mathrm{mg} / \mathrm{dl})$ & 14 & $2 \cdot 85$ & $1 \cdot 31$ & 128 & $3 \cdot 23$ & $2 \cdot 03$ & -0.67 & NS \\
\hline Serum Fe $(\mu g / d l)$ & 14 & $80 \cdot 2$ & $15 \cdot 5$ & 129 & $97 \cdot 4$ & $34 \cdot 5$ & $3 \cdot 34 *$ & $P<0.01$ \\
\hline
\end{tabular}

Transformed variables re-expressed as $\%:{ }^{15} \cdot 1,{ }^{25} \cdot 3,{ }^{3} 9 \cdot 6 .{ }^{4} 9 \cdot 1,{ }^{5} 8 \cdot 0,{ }^{6} 7 \cdot 9 .{ }^{*}$ Welch's test statistic (see text).

explore whether PSR status appeared to be influenced jointly by a combination of indices. This procedure also allowed the effect of age to be taken properly into account. Preliminary analyses indicated that platelets were unrelated to PSR, and since platelet levels were unavailable for many patients they were excluded from this analysis. The youngest patient with PSR in this sample was aged 21 , and the regression analysis was therefore restricted to patients aged 20 or over, i.e., the group thought to be at risk. There were 189 patients in this age group with steady-state values for all indices.
In males the analysis confirmed the association of high $\mathrm{Hb}$ and low $\mathrm{HbF}$ with PSR, but there was also a suggestion that high serum iron levels might be of importance. Among females neither $\mathrm{HbF}$ nor $\mathrm{Hb}$ appeared to be of importance; low iron levels appeared to be associated with PSR, but the contribution of this parameter to the fit of the regression model was marginal.

The above findings are illustrated in Figs. 1-6. In males (Fig. 1) the HbF levels of PSR cases were clustered in the lower part of the range, while no such effect was apparent in females (Fig. 2). Thus, all 15 male cases had $\mathrm{HbF}$ levels below $6^{\circ}$, while

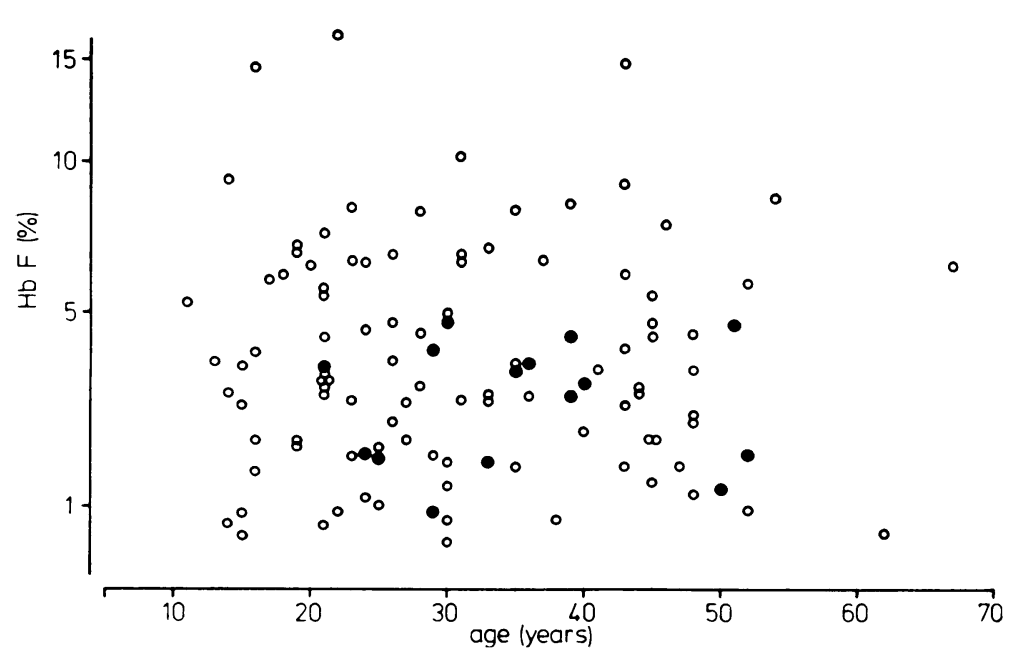

Fig. 1 HbF levels in male patients with (○) and without ( ) PSR. 
Fig. $2 \mathrm{HbF}$ levels in female patients with (O) and without (O) PSR.

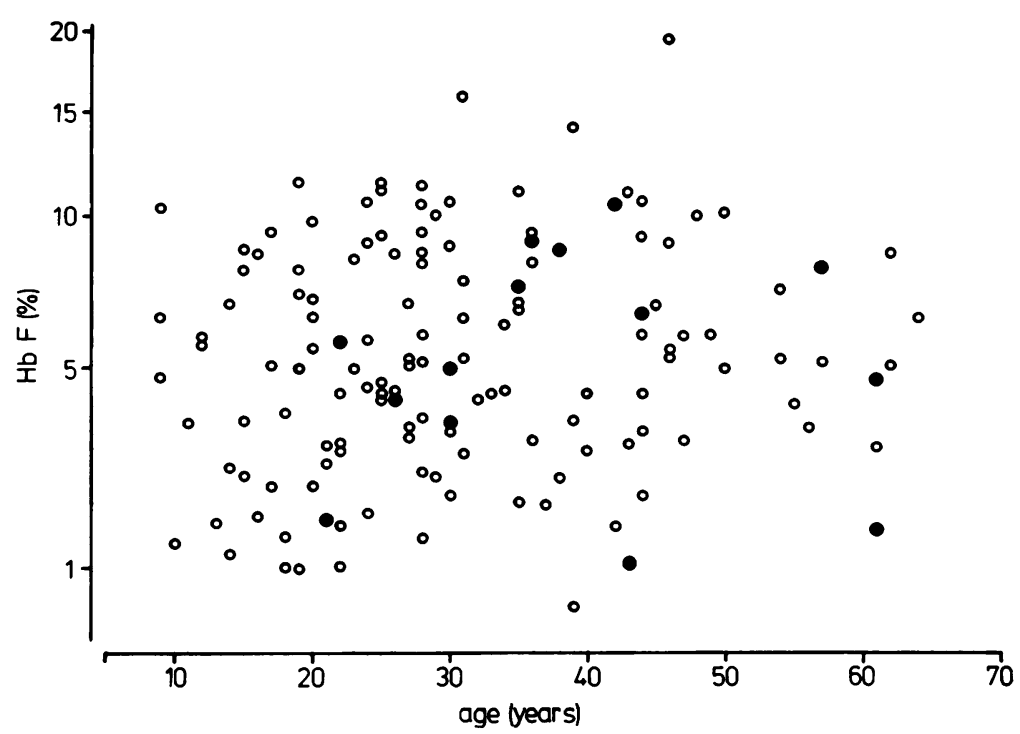

6/14 female cases had levels higher than this. Plots of total $\mathrm{Hb}$ levels against age indicated a strong tendency to lower $\mathrm{Hb}$ levels in patients over the age of $\mathbf{4 0}$ (Figs. 3 and 4). As onset of PSR is thought to occur most frequently at younger ages, ${ }^{5}$ the $\mathbf{H b}$ levels recorded in older patients may therefore not be representative of their levels at the time of onset of PSR. If attention is restricted to younger patients, it is evident that all the male cases were clustered at the upper end of the range of $\mathrm{Hb}$ values above $9 \mathrm{~g} / \mathrm{dl}$. The striking effect seen in males was not evident in females.
When the analysis was restricted to patients under the age of $\mathbf{4 0}$ years, the association of PSR with high haemoglobin and low HbF levels was clearly evident in males (Fig. 5) but not in females (Fig. 6). In male patients with PSR 10/11 had both high $\mathrm{Hb}(>9 \mathrm{~g} / \mathrm{dl})$ and low $\mathrm{HbF}(<5 \%)$ levels. The 1 male patient not falling into this pattern was 39 years old, and his $\mathrm{Hb}$ level may already have declined as a result of aging. Note that the majority of patients with $\mathrm{Hb}$ and $\mathrm{HbF}$ levels and age in the stated ranges had PSR lesions detected. Again the clear pattern evident in males was not repeated in
Fig. $3 \mathrm{Hb}$ levels in male patients with (O) and without (O) PSR.

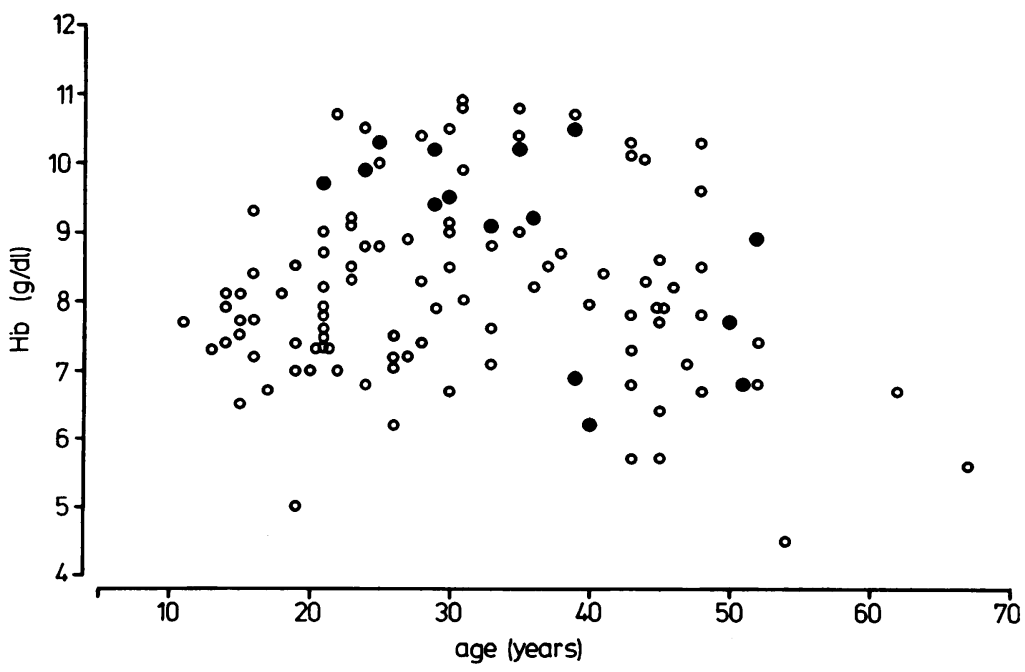




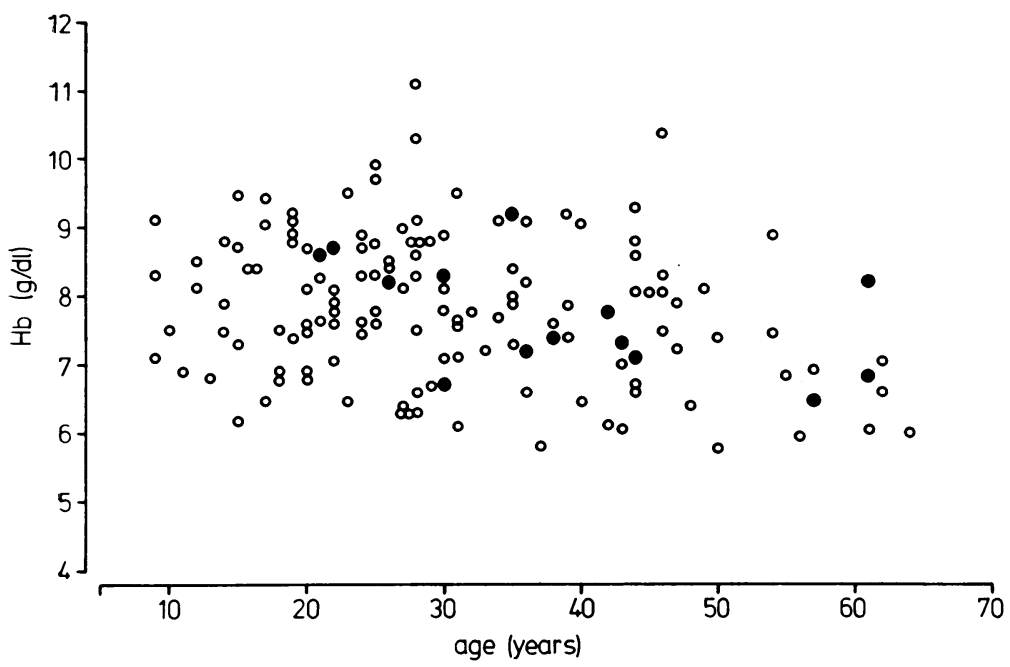

Fig. 4 Hb levels in female patients with (O) and without (O) PSR.

the female group, though higher than average $\mathrm{Hb}$ levels did occur in the few female cases under the age of 30 .

The contribution of iron was problematical. Scrutiny of the data suggested that the apparent contribution of high levels of serum iron to PSR in males may have resulted from just 3 PSR cases which had low levels of $\mathrm{Hb}$ but high levels of iron. All 3 were among the older patients, and, as has already been pointed out, current $\mathrm{Hb}$ levels may be unrepresentative of those at the time of onset. This observation, together with the discordance between the sexes in the direction of this effect, suggests that the apparent influence of iron should be treated with caution.
PROSPECTIVELY OBSERVED PROLIFERATIVE RETINOPATHY

As there is some evidence of longitudinal changes in haematological indices, difficulties in interpretation may arise in analyses employing haematological data collected years after the development of PSR. Further analyses were therefore performed in a small group of patients ( 4 male, 5 female) in whom the development of PSR has been prospectively recorded. Haematological indices in this group prior to onset were compared with those in 9 age/sex matched controls selected at random from the study group (Table 4).

The 4 male pairs fit clearly into the pattern outlined above. All 4 cases had high $\mathrm{Hb}$ and none had

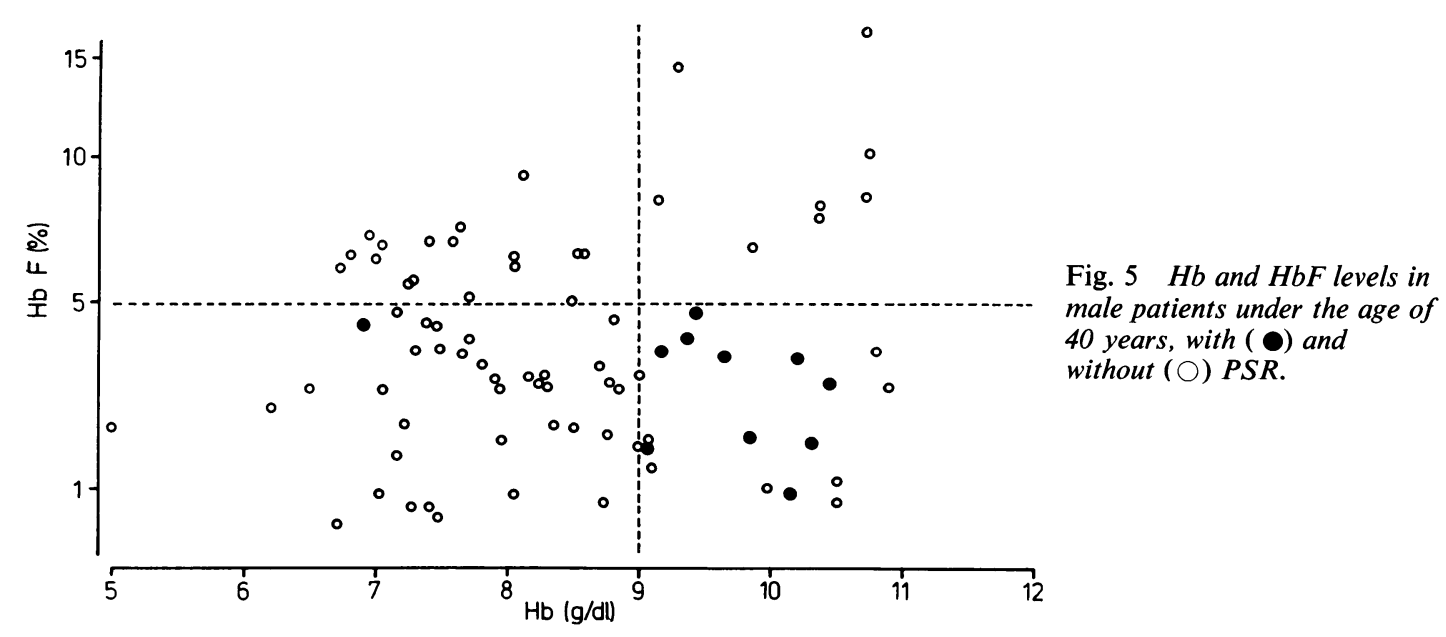


Fig. $6 \mathrm{Hb}$ and $\mathrm{HbF}$ levels in female patients under the age of 40 years, with $(\mathrm{O})$ and without ( $\bigcirc)$ PSR.

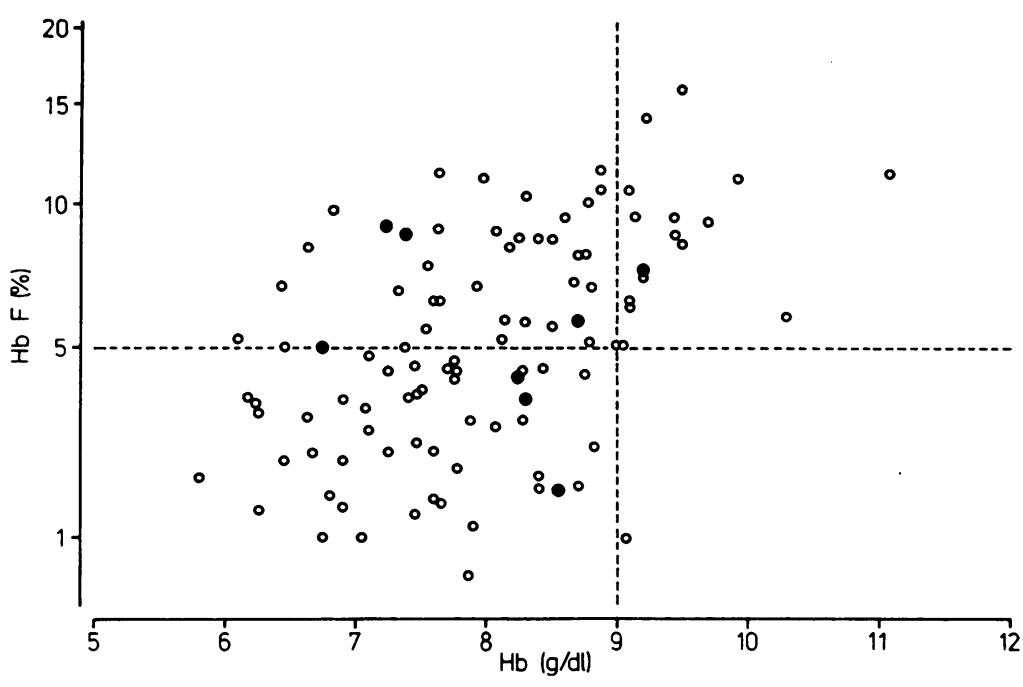

HbF levels above $4 \%$. In contrast, all 4 control patients had lower $\mathrm{Hb}$ levels and two had $\mathrm{HbF}$ levels above $6 \%$. There was no difference in mean iron levels between the 2 groups. Once again the female patients failed to follow this clear pattern. Mean $\mathrm{Hb}$ was slightly higher among the cases of PSR $(7.6 \mathrm{~g} / \mathrm{dl})$ than in the controls $(7.1 \mathrm{~g} / \mathrm{dl})$, but in 2 pairs out of 5 the $\mathrm{Hb}$ level was higher in the control patient. Furthermore, 4 out of 5 cases had HbF levels in excess of $6 \%$, a level which appears to have conferred protection in the male group.

\section{Discussion}

Proliferative retinopathy represents a permanent change in the retinal vasculature which, even if autoinfarcted and no longer leaking fluorescein, is still recognisable on ophthalmoscopy. The prevalence of PSR in the clinic population might therefore be expected to increase progressively with age. In this sample the highest proportion of patients with PSR occurred in the 30-39 year age group, but biases in patient selection will have overestimated

Table 4 Haematological indices of PSR cases with known age of onset, and age/sex matched controls

\begin{tabular}{|c|c|c|c|c|c|c|c|c|c|c|}
\hline Males & Case & Control & Case & Control & Case & Control & Case & Control & & \\
\hline Age of onset & 20 & & 26 & & 27 & & 30 & & & \\
\hline HbF $(\%)$ & $3 \cdot 5$ & $6 \cdot 8$ & 2.9 & $0 \cdot 3$ & $1 \cdot 3$ & $3 \cdot 8$ & 0.7 & $7 \cdot 8$ & & \\
\hline $\mathrm{Hb}(\mathrm{g} / \mathrm{dl})$ & $8 \cdot 8$ & $8 \cdot 1$ & $9 \cdot 2$ & $6 \cdot 6$ & $10 \cdot 6$ & $7 \cdot 5$ & $10 \cdot 6$ & $7 \cdot 7$ & & \\
\hline $\operatorname{MCHC}(\mathrm{g} / \mathrm{dl})$ & $33 \cdot 0$ & $29 \cdot 5$ & $31 \cdot 5$ & $31 \cdot 8$ & $31 \cdot 7$ & $32 \cdot 8$ & $33 \cdot 0$ & $33 \cdot 8$ & & \\
\hline $\operatorname{MCV}(f)$ & - & - & 86 & 84 & 78 & 98 & 84 & 97 & & \\
\hline Serum $F e(\mu g / d l)$ & 166 & 93 & 74 & 62 & 64 & 126 & 83 & 100 & & \\
\hline Females & Case & Control & Case & Control & Case & Control & Case & Control & Case & Control \\
\hline Age of onset & 21 & & 34 & & 39 & & 42 & & 44 & \\
\hline $\mathrm{HbF}(\%)$ & $7 \cdot 0$ & $5 \cdot 8$ & $8 \cdot 8$ & $3 \cdot 3$ & $1 \cdot 1$ & $11 \cdot 0$ & $10 \cdot 4$ & $1 \cdot 6$ & $6 \cdot 5$ & $3 \cdot 5$ \\
\hline $\mathrm{Hb}(\mathrm{g} / \mathrm{dl})$ & $8 \cdot 4$ & $6 \cdot 8$ & $7 \cdot 2$ & $6 \cdot 5$ & $7 \cdot 5$ & $6 \cdot 0$ & $7 \cdot 8$ & $8 \cdot 4$ & $7 \cdot 1$ & $7 \cdot 9$ \\
\hline $\operatorname{MCHC}(g / d l)$ & $33 \cdot 0$ & $32 \cdot 3$ & $31 \cdot 4$ & $32 \cdot 0$ & $31 \cdot 8$ & $32 \cdot 0$ & $33 \cdot 8$ & $31 \cdot 8$ & $32 \cdot 3$ & $32 \cdot 6$ \\
\hline $\operatorname{MCV}(f)$ & 94 & 97 & 94 & 85 & 77 & 102 & 94 & 82 & 94 & 88 \\
\hline Serum $F e(\mu g / d l)$ & 88 & 120 & 104 & 60 & 69 & 121 & 110 & 76 & 74 & 100 \\
\hline
\end{tabular}


the prevalence of PSR in both the 20-29 and 30-39year age groups. Thus of the group of 76 unselected patients originally examined ${ }^{1} 71$ were under the age of 40 years, and only 1 of these had PSR. In the present study PSR occurred in 10/71 (14\%) patients over the age of 40 years, and this is probably a valid estimate of the prevalence in this age group, as ophthalmological assessments are routine in these patients.

Apart from age, which reflects duration of the vaso-occlusive process and the accumulation of end organ damage, it was possible to identify other factors associated with the occurrence of PSR. Both high haemoglobins and low fetal haemoglobin levels were significantly related to PSR in male patients, but such analyses were complicated by age-related effects. Total haemoglobin appeared to fall with age beyond the age of 40 years in essentially cross-sectional studies (Fig. 3), and this is probably true of longitudinal observations in individual patients. The mechanisms responsible for this fall are unclear, though the increasing prevalence of chronic renal failure in older patients with SS disease is one of the factors responsible. Since PSR appears to develop in male patients most frequently between the ages of 20 and 30 years, analyses based on the haemoglobin level present 10-30 years later may be fallacious. Such errors are reduced by confining analysis to patients aged under 40 years. In this context the effects of total $\mathrm{Hb}$ and $\mathrm{HbF}$ in male patients are striking. Of male patients with $\mathrm{Hb}$ levels $>9.0 \mathrm{~g} / \mathrm{dl}, 10 / 26$ had PSR, and of those with $\mathrm{Hb}$ levels $>9.0 \mathrm{~g} / \mathrm{dl}$ and $\mathrm{HbF}$ levels $<5 \%, 10 / 18$ had PSR. Indeed 10/11 patients with PSR fell in this latter group. In the high haemoglobin group no cases of PSR occurred among the 8 patients with $\mathrm{HbF}$ levels $>5 \%$ (Fig. 5), suggesting that high levels of $\mathrm{HbF}$ may confer a protective effect.

The lack of similar relationships in female patients is disappointing, though it is of interest to note that no female patients had indices in the 'high risk' group $(\mathrm{Hb}>9.0 \mathrm{~g} / \mathrm{dl} ; \mathrm{HbF}<5 \%)$ as defined from male patients. Of the female patients who had developed PSR, however, some had lower $\mathrm{Hb}$ and higher $\mathrm{HbF}$ levels than were seen among male patients with PSR. No clear relationships with haematological indices were apparent, and it is possible that a different mechanism is involved in female patients.

Mechanisms whereby high haemoglobins and low fetal haemoglobin levels might influence the development of PSR are speculative. Viscosity increases in proportion to the haematocrit in in-vitro studies, though the haematocrit may have little effect on viscosity in capillaries. However, the haemoglobin level appears to influence blood flow in some peripheral capillary beds in patients with normal red blood cells, ${ }^{9-10}$ and it is possible that haemoglobin level plays a greater role in the presence of the decreased deformability of sickled cells. The $\mathrm{HbF}$ level is inversely related to the proportion of irreversibly sickled cells, ${ }^{11}$ and it is probable that patients in the 'high risk' group $(\mathrm{Hb}>9.0 \mathrm{~g} / \mathrm{dl}$; $\mathrm{HbF}<5 \%$ ) have compromised blood flow from both a relatively high haemoglobin level and a high proportion of sickled cells.

Difficulties of interpretation arose in this study because the haematology of some patients with PSR may have been recorded several years after the onset of PSR, whereas the haematology immediately prior to onset is likely to be more relevant. Nevertheless the observation that current levels of $\mathrm{Hb}$ or $\mathrm{HbF}$ are particularly high or low in patients with PSR is at least suggestive of a causal link with these variables. A more sensitive test of this hypothesis will become available with prospective studies recording the development of proliferative retinopathy which are currently in progress.

\section{References}

1 Condon PI, Serjeant GR. Ocular findings in homozygous sickle cell disease in Jamaica. Am J Ophthalmol 1972; 73: 533-43.

2 Condon PI, Serjeant GR. Ocular findings in hemoglobin SC disease in Jamaica. Am J Ophthalmol 1972; 74: 931-41.

3 Condon PI, Serjeant GR. Ocular findings in sickle cell thalassemia in Jamaica. Am J Ophthalmol 1972; 74: $1105-9$.

4 Condon PI, Serjeant GR. The progression of sickle cell eye disease in Jamaica. Doc Ophthalmol 1975; 39: 203-10.

5 Condon PI, Serjeant GR. The behaviour of untreated proliferative sickle retinopathy. $\mathrm{Br} J$ Ophthalmol 1980; 64: 404-11.

6 Serjeant GR. The Clinical Features of Sickle Cell Disease. Amsterdam: North Holland, 1974: 59-62.

7 Pearson ES, Hartley HO, eds. Biometrika Tables for Statisticians. 2nd ed. London: Cambridge University Press, 1958: 1: 26-7.

8 Nelder JA, Wedderburn RWM. Generalised linear models. J R Statist Soc $(A)$ 1972; 135: 370-84.

9 Thomas DJ, du Boulay GH, Marshall J, et al. Effect of haematocrit on cerebral blood flow in man. Lancet, ii: 941-3.

10 Tohgi H, Yamanouchi H, Murakami M, Kameyama M. Importance of the haematocrit as a risk factor in cerebral infarction. Stroke 1978; 9: 369-74.

11 Serjeant GR. Irreversibly sickled cells and splenomegaly in sickle cell anaemia. Br J Haematol 1970; 19: 635-41. 